\title{
PURIFICACIÓN Y CARACTERIZACIÓN DE UNA HEMORRAGINA DE ALTO PESO MOLECULAR PRESENTE EN EL VENENO DE LA SERPIENTE Bothrops pictus
}

\author{
Candy Bellido, Fanny Lazo, César Ortiz, Edith Rodríguez, Armando Yarlequé*
}

\section{RESUMEN}

\begin{abstract}
A partir de veneno total de la serpiente Bothrops pictus se ha purificado una hemorragina con actividad de metaloproteasa, usando una columna de filtración molecular sobre Sephadex G-75 y otra de intercambio aniónico sobre DEAE Sephadex A-50, equilibradas con buffer acetato de amonio $0,1 \mathrm{M} \mathrm{pH} 5$. La proteína en estudio fue obtenida al estado homogéneo con un peso molecular de $62 \mathrm{kDa}$ y es de naturaleza ácida, ataca tanto a la caseína como a la gelatina y es inhibida por EDTA, $2 \beta$-mercaptoetanol y DTT. La dosis hemorrágica mínima (DHM) de la proteína purificada fue de $0,226 \mu \mathrm{g}$ y esta actividad fue reducida por los mismos agentes. Su pH óptimo es de 7,5 y su estabilidad térmica le permite mantener el 30,4\% de su actividad luego del calentamiento a $55{ }^{\circ} \mathrm{C}$. La hemorragina de $B$. pictus reacciona con el antiveneno botrópico polivalente, generando líneas de precipitina en pruebas de inmunodifusión doble y es neutralizada por el antiveneno usando $0,5,1$ y 2 dosis.
\end{abstract}

Palabras clave: Hemorragina, veneno, serpiente, metaloproteasa, caseína.

\section{A PURIFICATION AND CHARACTERIZATION OF HIGH MOLECULAR WEIGHT HEMORRHAGIN PRESENT IN THE SNAKE VENOM Bothrops pictus}

\begin{abstract}
A hemorrhagin with metalloprotease activity was purified from the venom of Bothrops pictus snake using Sephadex G-75 molecular gel filtration and DEAE A-50 ionic exchange column. Thus a homogeneus protein entity was obtained with $62 \mathrm{kDa}$ under non reducting conditions. Hemorrhagin is a acid protein, attack both casein and collagen being 0,226 $\mu \mathrm{g}$ as a DHM. Chelating agent such as EDTA as well as $2 \beta$-mercaptoetanol and DTT produced strong inhibition both caseinolitic and hemorrhagic activities. Optimus $\mathrm{pH}$ was 7,5 and heating treatment reduced both activities, At $55^{\circ} \mathrm{C}$ recovered activity on casein was $30,4 \%$. On the other hand hemorrhagin is an antigenic entity showed on double immunodiffusion test and was neutralizated fulling with $0,5,1$ and 2 doses of antivenom.
\end{abstract}

Key words: Snake, venom, Bothrops pictus, metalloprotease, hemorrhage, proteolytic.

a *Laboratorio de Biología Molecular-Facultad de Ciencias Biológicas, UNMSM. Av. Venezuela Cdra. $34 \mathrm{~s} / \mathrm{n}$.

Lima 1.Perú. Teléfono: 6197000 Anexo 1528/1558. Email: ayarleque48@gmail.com 


\section{INTRODUCCIÓN}

El veneno de serpiente es una mezcla altamente compleja que contiene diversas proteínas, principalmente enzimas, así como nucleótidos, iones metálicos y pigmentos ${ }^{1}$, los cuales, en conjunto, ocasionan el cuadro de envenenamiento ofídico.

La sintomatología general del envenenamiento producido por las especies del Bothrops es la de originar efectos locales que incluyen edema, dolor, hemorragia, necrosis e infiltración de leucocitos ${ }^{2}$, en tanto que, los efectos sistémicos incluyen coagulopatías, hemorragia sistémica, nefrotoxicidad y cardiotoxicidad, lo cual puede conllevar a la muerte de la víctima ${ }^{3}$ Estos efectos son causados principalmente por metaloproteasas, serinoproteasas, fosfolipasas, desintegrinas, lectinas, entre otras proteínas.

Actualmente, se sabe que aproximadamente el $30 \%$ del contenido del veneno de los vipéridos son metaloproteasas, por lo que estas enzimas estarían fuertemente ligadas al proceso de envenenamiento, en particular al efecto hemorrágico así como a la degradación de proteínas tisulares y plasmáticas ${ }^{4}$. Los estudios sobre la hemorragia causada por la mordedura de vipéridos, indica que se trata de uno de los efectos más severos ya que se originan daños irreversibles en el tejido vascular, lo que posteriormente conduce a la necrosis.

En un estudio realizado por Olascoaga ${ }^{5}$, a partir del veneno completo de B. pictus, se determinaron diferentes actividades, tales como, actividad proteolítica, fosfolipásica, hemorrágica, edematizante, entre otras. Recientemente, Kohlhoff et al. ${ }^{6}$, empleando métodos proteómicos determinaron la presencia de aproximadamente ocho metaloproteasas en el veneno de esta serpiente. Sin embargo, poco se sabe aún sobre la acción hemorrágica de algunas de estas proteasas, ya que hasta la fecha no se había aislado ninguna.

Por tanto, el objetivo de la presente investigación fue explorar la presencia de metaloproteasas hemorrágicas del veneno de la serpiente peruana Bothrops pictus y caracterizar la de mayor actividad hemorrágica desde el punto de vista bioquímico y biológico.

\section{PARTE EXPERIMENTAL}

1. Veneno y antiveneno.- Fue obtenido al estado liofilizado de especímenes adultos de Bothrops pictus, procedentes de la localidad de Canta (Lima), mantenidos en cautiverio en el Serpentario "Oswaldo Meneses" de la UNMSM.

El antiveneno usado fue antibotrópico comercial (INS) Lote N0. 00300078.

2. Cuantificación de proteínas.- Se calculó midiendo espectrofotométricamente la absorbancia a $280 \mathrm{~nm}^{7}$, y por el método de Lowry et al., $1951^{8}$, modificado por Loayza et al., $1985^{9}$ empleando albúmina sérica bovina como proteína estándar y midiendo la reacción a $660 \mathrm{~nm}$.

3. Actividad proteolítica y hemorrágica.- La actividad proteolítica fue medida sobre caseína al $1 \%$, siguiendo la técnica de Takahashi y Osaka, $1970^{10}$. Adicionalmente, esta 
actividad fue evaluada en zimogramas de geles de acrilamida-gelatina, verificándose la banda de hidrólisis en los geles (Antunes, et al., 2010 11 ).

La actividad hemorrágica fue estimada por el método de Kondo et al., $1960^{12}$ modificado por Isla, et al., $2003^{13}$, en el cual se determina el área hemorrágica en piel de ratón albino cepa Balb c, luego de dos horas de la inoculación. La dosis hemorrágica mínima (DHM) corresponde a la cantidad de proteína que origina un área hemorrágica de $10 \mathrm{~mm}$ de diámetro.

4. Purificación de la metaloproteasa y peso molecular.- $50 \mathrm{mg}$ de veneno de Bothrops pictus disueltos en buffer acetato de amonio $0,1 \mathrm{M} \mathrm{pH} 5$ y aplicados a una columna de filtración molecular sobre Sephadex G-75 usando el mismo buffer. Las fracciones con actividad proteolítica fueron aplicadas luego a una columna de intercambio aniónico sobre DEAE Sephadex A-50 equilibrada con el mismo buffer y eluída con una gradiente lineal de $\mathrm{NaCl} 0$ - 0,3M. En la fracción obtenida se midió la actividad sobre caseína y la acción hemorrágica.

La fracción purificada fue evaluada por el método de Laemmli et al., 1970 ${ }^{14}$, mediante electroforesis por PAGE-SDS en condiciones no reductoras, usando una cámara vertical Techware (Sigma) a un voltaje constante de $100 \mathrm{~V}$ por una hora. Los geles fueron teñidos con azul brillante de Coomasie 0,05\% y se emplearon proteínas, marcadoras de peso molecular en el rango de 7 a $240 \mathrm{kDa}$.

5. Inhibidores proteolíticos.- Se mezclaron $100 \mu \mathrm{L}$ de la proteína en estudio y $100 \mu \mathrm{L}$ del agente inhibidor a concentraciones finales de 5 y $10 \mathrm{mM}$. El agente quelante empleado fue EDTA (Ácido etilen diamino tetra acético) y los agentes reductores fueron: 2 mercaptoetanol y DTT (Ditiotreitol). Luego de 10 minutos de preincubación, se midió la actividad proteolítica sobre caseína.

6. Determinación del pH óptimo y termoestabilidad.- Se calculó utilizando buffer Tris $\mathrm{HCl}$ 0,2 M en un rango de $\mathrm{pH}$ de 7,0 a 9,0, usando caseína como substrato. Asimismo, la estabilidad térmica fue medida a diferentes temperaturas en el rango de 37 a $75^{\circ} \mathrm{C}$.

7. Antigenicidad y neutralización.- Se realizó por el método de inmunodifusión de Ouchterlony y Nilsson, 197815, usando placas de agarosa al 1\% conteniendo la fracción proteolítica y el antiveneno y visualizando la línea de precipitina luego de la coloración con azul brillante de Coomassie al $0,05 \%$.

En cuanto a la neutralización de la actividad proteolítica-hemorrágica fue medida usando mezclas enzima-antiveneno $(0,5,1$ y 2 dosis), de acuerdo con la metodología descrita por Yarlequé et al., $2008^{16}$.

\section{RESULTADOS}

1. Purificación de la metaloproteasa hemorrágica

El primer paso de purificación empleando una columna de filtración molecular sobre Sephadex G-75, reveló cuatro picos de proteínas (figura 1); coincidiendo el primer pico con la actividad proteolítica. 


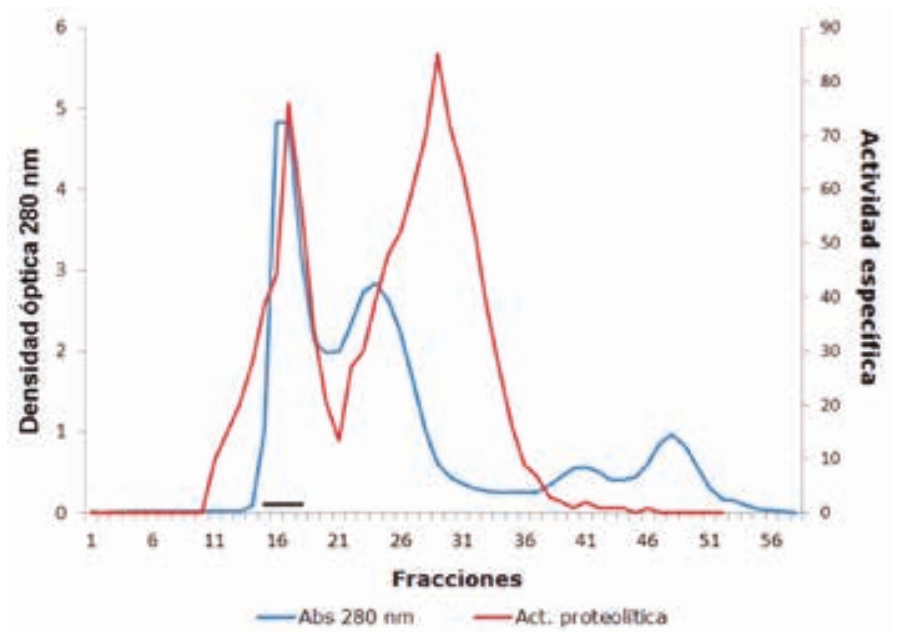

Figura 1. Primer paso de purificación empleando cromatografía de filtración molecular sobre Sephadex G-75.

El segundo paso usando una columna de intercambio aniónico sobre DEAE-Sephadex A-50 dio lugar a la separación de la fracción proteolítica- hemorrágica al aplicar $\mathrm{NaCl} 0,3 \mathrm{M}$ (figura 2).

El análisis electroforético mostró una sola banda proteica con un peso molecular de $62 \mathrm{kDa}$ en condiciones no reductoras, por lo que se deduce que se trata de una hemorragina de alto peso molecular.

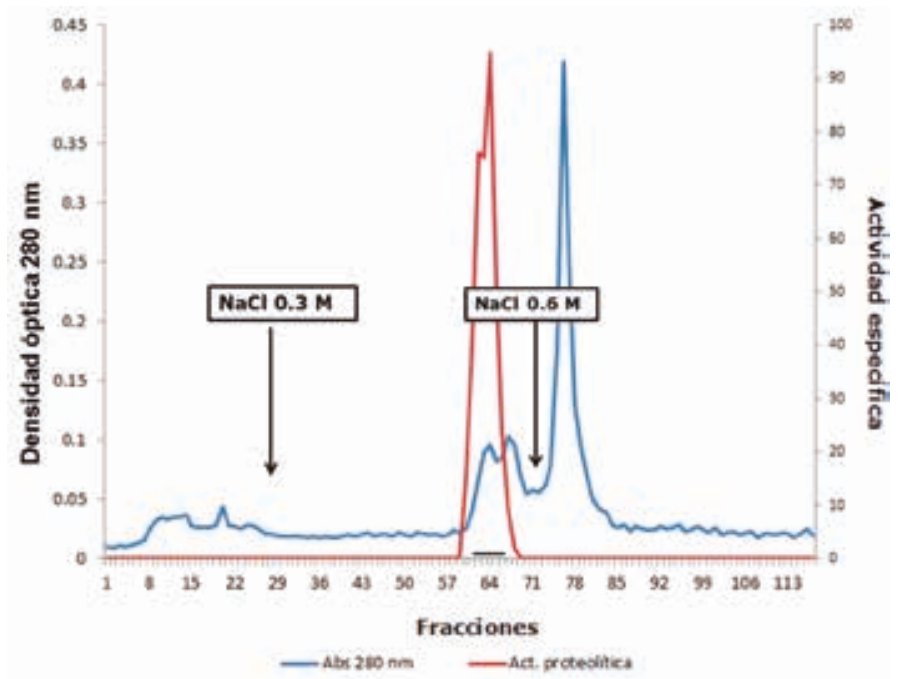

Figura 2. Segundo paso de purificación empleando cromatografía de intercambio aniónico sobre DEAE Sephadex A-50. 


\section{Actividades proteolítica y hemorrágica}

El análisis de la actividad sobre caseína dio un valor de 74,1 U/mg de proteína en tanto que, la actividad sobre gelatina se verificó por la hidrólisis en geles de poliacrilamida, encontrándose una banda de digestión de $62 \mathrm{kDa}$ que coincidía con el peso de la enzima purificada. Asimismo, la actividad hemorrágica fue estimada en 0,226 $\mu \mathrm{g}$ lo que corresponde a una DHM. Este valor es 2,4 veces mayor que la DHM del veneno total (figura 3).

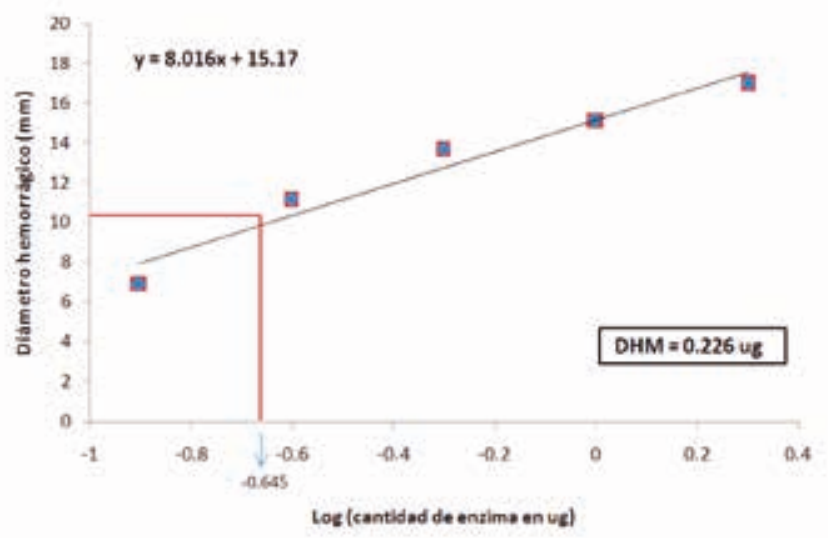

Figura 3. Determinación de la dosis hemorrágica mínima (DHM) de la metaloproteasa hemorrágica aislada del veneno de Bothrops pictus

\section{Inhibidores}

Los ensayos con EDTA, 2 $\beta$ - marcaptoetanol y DTT a la concentración de $5 \mathrm{mM}$, redujeron la actividad caseinolítica a 45,29, 67,4 y 69,2\%, respectivamente, mientras que a $10 \mathrm{mM}$ los valores fueron $21,32,2$ y $32,5 \%$, respectivamente. De modo paralelo se observó una marcada reducción del efecto hemorrágico luego del tratamiento con estos agentes (tabla 1).

Tabla 1. Efecto de agentes inhibidores sobre la actividad proteolítica y acción hemorrágica.

\begin{tabular}{|c|c|c|c|}
\hline \multirow[t]{2}{*}{ AGENTE } & \multirow[t]{2}{*}{ mM } & \multicolumn{2}{|c|}{ ACTIVIDAD } \\
\hline & & $\begin{array}{c}\text { CASEINOLÍTICA } \\
(\%)\end{array}$ & HEMORRÁGICA* \\
\hline CONTROL & --- & 100 & +++ \\
\hline \multirow[t]{2}{*}{ EDTA } & 5 & 45,29 & ++ \\
\hline & 10 & 21,00 & - \\
\hline \multirow[t]{2}{*}{ 2B-mercaptoetanol } & 5 & 67,4 & ++ \\
\hline & 10 & 32,2 & + \\
\hline \multirow[t]{2}{*}{ DTT } & 5 & 69,2 & ++ \\
\hline & 10 & 32,5 & + \\
\hline
\end{tabular}




\section{4. pH óptimo y termoestabilidad}

La actividad caseinolítica se registró en el rango de $\mathrm{pH} 7$ a 9, con un valor máximo a pH 7,5. Asimismo, el tratamiento a temperaturas en el rango de 37 a $75^{\circ} \mathrm{C}$ dio lugar a una progresiva pérdida de la actividad enzimática y hemorrágica; de manera que a $55^{\circ} \mathrm{C}$ sólo se registró el $30,4 \%$ de la actividad inicial y una pobre acción hemorrágica. A $75^{\circ} \mathrm{C}$ no se registró ni actividad caseinolítica ni acción hemorrágica (figura 4).

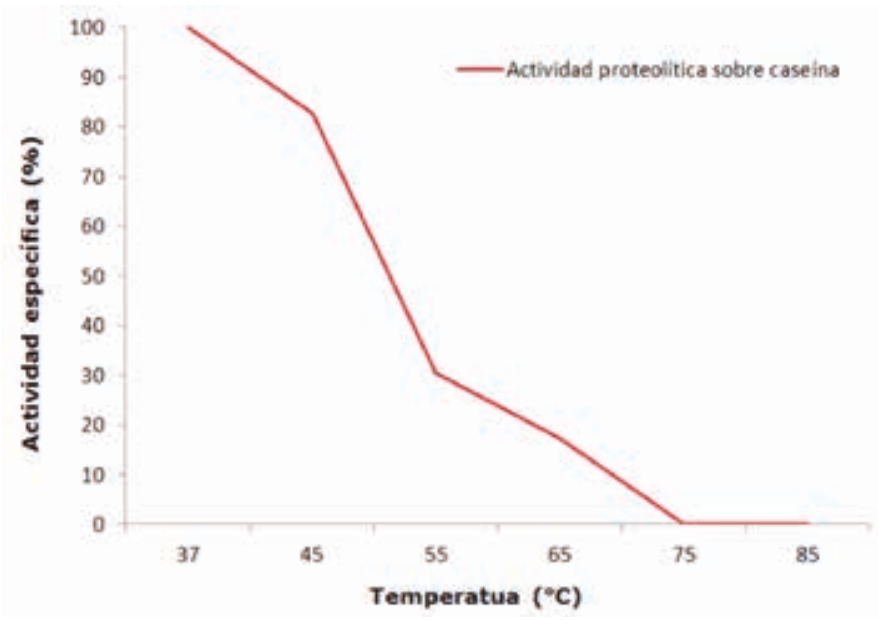

Figura 4. Efecto de la temperatura sobre la actividad proteolítica de la metaloproteasa aislada del veneno de Bothrops pictus.

\section{Antigenicidad y neutralización}

La hemorragina de $B$. pictus mostró su reactividad antigénica al formar una línea de precipitina con el antiveneno botrópico polivalente en ensayos de inmunodifusión. Asimismo, la preincubación de la proteína en estudio con el equivalente de $0,5,1$ y 2 dosis del antiveneno botrópico comercial generó una total neutralización tanto de su actividad enzimática como hemorrágica.

\section{DISCUSIÓN}

Teniendo en cuenta la actual clasificación de las metaloproteasas ofídicas, de acuerdo a la organización de sus dominios, ellas pertenecen a las clases PI, PII y PIII. La habilidad para producir hemorragia durante el proceso de envenenamiento es atribuida a las tres clases, sin embargo, la clase PIII es la que presenta mayor actividad hemorrágica² ${ }^{2}$

El método de purificación usado (figuras 1 y 2 ) señala que la principal hemorragina de este veneno ha sido obtenida al estado homogéneo con un peso molecular de $62 \mathrm{kDa}$; este valor corresponde a proteínas de alto peso molecular que, en el caso de las metaloproteasas son de la Clase P-III; es decir hemorraginas con actividad proteolítica. 
Varias metaloproteasas de la clase PIII han sido purificadas, y una de las más estudiadas es la aislada de Bothrops jararaca, que tiene un peso molecular de $52 \mathrm{kDa}$ determinado por PAGE-SDS.

En el 2012, Kohlhoff, et al. ${ }^{6}$ realizaron un estudio proteómico sobre tres especies del género Bothrops que habitan en el Perú, B. atrox, B. barnetti y B. pictus; en esta última se encontraron ocho metaloproteasas y se les determinó su masa molecular. Entre las metaloproteasas encontradas en este veneno se muestran dos con pesos moleculares de $60 \mathrm{y}$ otra de $65 \mathrm{kDa}$ por electroforesis en PAGE-SDS, tanto en condiciones reductoras como no reductoras, una de las cuales correspondería a la enzima purificada en este estudio.

En la especie B. atrox, se han aislado metaloproteasas de peso molecular bajo ${ }^{17} \mathrm{y}$ alto ${ }^{18}$, que corresponderían a las clases PI y PIII, respectivamente. En B. pictus, previamente se había encontrado una metaloproteasa con un peso molecular de $50 \mathrm{kDa}$ bajo condiciones reductoras y no reductoras, por lo que se trata de una enzima unicatenaria, no hemorrágica ${ }^{19}$.

La actividad proteolítica de la enzima purificada fue evaluada por dos métodos conocidos: la actividad caseinolítica y la zimografía, que emplea a la gelatina como sustrato. En la actividad caseinolítica se mide los productos ácido solubles originados por la enzima y con esta técnica se han identificado varias proteasas: Lachesis muta ${ }^{20}$, Bothrops atrox ${ }^{17}, B$. brazili $^{21}, B$. pictus ${ }^{19}$, Trimeresurus flavoviridis ${ }^{10}$. A su vez, la zimografía sobre gelatina es un método que mide la proteólisis del colágeno, debido a que la gelatina se produce a partir de su desnaturalización, lo cual se encontraría altamente relacionada con la degradación de la matriz extracelular.

Nuestros resultados muestran actividad proteolítica sobre gelatina, en donde se pudo observar la degradación de la gelatina obtenida por la enzima purificada y que también se observó en el veneno crudo.

En las metaloproteasas se ha evidenciado la presencia de un "binding pocket" en el dominio catalítico altamente flexible, lo cual permite que estas enzimas muestren una amplia especificidad de sustrato ${ }^{4}$ ). En otras palabras, se puede emplear una variedad de sustratos, siendo la caseína (proteína genérica) y la gelatina (proteína específica derivada del colágeno) muy eficientes para evaluar esta actividad.

En el presente trabajo se pudo obtener una enzima con alta acción hemorrágica debido a que se trataría de una metaloproteasa de la clase PIII. Por otro lado, se han podido aislar proteasas hemorrágicas de las serpientes Bothrops atrox, B. jararacá, Crotralus atrox, $B$. jararacussu ${ }^{22}$, entre otras, y esa capacidad hemorrágica se ha atribuido tanto a los dominios catalíticos como a los no catalíticos. La existencia de actividad proteolítica no demarca una acción hemorrágica correlativa, esto se puede observar en la presente enzima purificada que tiene actividad proteolítica baja, sin embargo, muestra actividad hemorrágica mayor en comparación con la enzima aislada por $\mathrm{Cortez}^{19}$. 
La DHM de la metaloproteasa purificada fue de $0,226 \mu \mathrm{g}$, que representa 2,4 veces más que en el veneno crudo de B. pictus cuyo DHM fue de 0,535 $\mu \mathrm{g}$. Asimismo, se ha encontrado que la metaloproteasa aislada de $B$. jararacussu tiene un DHM de $4 \mu \mathrm{g}^{(22)}$ y la de $B$. brazili, un DHM de $6 \mu \mathrm{g}^{13}$.

La temperatura es un factor importante para que una enzima mantenga su actividad, ya que al incrementarla, la enzima cambia su conformación. La composición aminoacídica de la proteína también es determinante en la estabilización de la enzima a altas temperaturas. Es así que, los aminoácidos hidrófobos dan mayor estabilidad a la enzima a diferencia de los aminoácidos hidrófilos. Además, cuando menor peso molecular muestre una proteína y mayor sea la cantidad de enlaces disulfuro, la proteína es más termoestable.

En cuanto a la estabilidad térmica de la proteína en estudio, se observó que su mayor actividad se encuentra a los $37^{\circ} \mathrm{C}$ y que a $55^{\circ} \mathrm{C}$ aún mantiene el $30 \%$ de actividad remanente (figura 4). Habiéndose observado un $\mathrm{pH}$ óptimo de 7,5, esto sugiere que la enzima se encuentra en su máxima actividad a $\mathrm{pH}$ sanguíneo, degradando eficientemente diversas proteínas circulatorias.

Por otro lado, la enzima del presente estudio mostró una disminución cercana al $80 \%$ empleando el agente quelante EDTA que es el principal inhibidor de la actividad enzimática de metaloproteasas ya que retira de modo irreversible los iones divalentes zinc o calcio, que forman parte de la estructura proteica. En cambio, agentes reductores como el $2 \beta$-mercaptoetanol y el DTT causan inhibición por acción a nivel de los residuos de cisteína que forman parte de los puentes disulfuro, por lo que se deduce que nuestra proteína en estudio contiene más de un enlace de este tipo.

Por último, es interesante señalar que la proteasas hemorrágica aislada es fuertemente antigénica ya que reconoce al antiveneno botrópico comercial y a su vez es totalmente neutralizada por el antiveneno aun a dosis bajas, lo que asegura la eficiencia de este producto en un caso de envenenamiento por esta serpiente.

\section{CONCLUSIONES}

La proteasa hemorrágica, aislada del veneno de Bothrops pictus, es una metaloenzima, sujeta al efecto de agentes reductores debido a la probable presencia de puentes S-S. Estas proteínas no sólo son de utilidad para la investigación del envenenamiento sino como herramientas en el análisis de procesos biológicos diversos como la agregación plaquetaria y la apoptosis.

\section{AGRADECIMIENTOS}

Los autores de la presente investigación agradecen al Vicerrectorado de Investigación de la UNMSM, por el apoyo financiero brindado para la ejecución de este trabajo. Uno de los 
autores (C. Bellido) obtuvo su título profesional de Bióloga Biotecnóloga Genetista con parte de esta investigación.

\section{REFERENCIAS BIBLIOGRÁFICAS}

1. Koh D, Armugam A, Jeyaseelan K. Snake venom components and their applications in biomedicine. Cell Mol Life Sci. 2006; 63(24): 3030-3041.

2. Fox J, Serrano S. Snake Venom Metalloproteinases. En: MacKessy, Stephen. Handbook of Venoms and toxins of reptils. Boca Raton: CRC Press; 2010. p. 95-113

3. Gutiérrez J, Rucavado A, Escalante T. Snake Venom Metalloproteinases: Biological Roles and Participation in the Pathophysiology of Envenomation. En: Mackessy, Stephen. Handbook of Venoms and toxins of reptiles. Boca Raton: CRC Press; 2010. p. 115-138.

4. Takeda S, Takeya H, Iwanaga S. Snake venom metalloproteinases: Structure, function and relevance to the mammalian ADAM/ADAMTS family proteins. Biochim Biophys Acta. 2012; 1824: 164-176.

5. Olascoaga M. Estudio del veneno de Bothrops pictus. Bioquímica, toxicidad, neutralización y efectos biológicos. [Tesis de pregrado]. Lima: Universidad Nacional Mayor de San Marcos; 1987

6. Kohlhoff M, Borges, Yarlequé A, Cabezas C, Richardson M, Sanchez E. Exploring the proteomes of the venoms of the Peruvian pit vipers Bothrops atrox, B. barnetti and Bothrops pictus. J Proteomics. 2012; 75(7): 2181-95.

7. Warburg $\mathrm{O}$, Christian W. Isolation ADN crystallization of the glycolytic enzyme enolase. Biochem Z. 1941; 31: 384-421.

8. Lowry O, Rosebrough N, Farr A, Randall R. Protein measurement with the Folin phenol reagent. J Biochem. 1951; 193: 165-275.

9. Loayza S, Morante Y, Campos S, Yarlequé A. Enzimas proteolíticas en el veneno de las serpientes peruanas Lachesis muta y Bothrops atrox. Bol Soc Quím Perú. 1985; 52(3):151-63.

10. Takahashi T, Ohsaka A. Purification and characterization of a proteinase in the venom of Trimeresurus flavoviridis. Complete separation of the enzyme from hemorrhagic activity. Biochim Biophys Acta. 1970; 198(2): 293-307.

11. Antunes T, Yamashita K, Barbaro K, Saiki M, Santoro M. Comparative analysis of newborn and adult Bothrops jararaca snake venoms. Toxicon; 2010; 56: 1443-1458.

12. Kondo H, Kondo S, Ikesawa M, Muta R, Ohsaka, A. Studies on the quantitative method for determination of hemorrhagic activity of Habu snake venom. Jpn J Med Sci Biol. 1960; 13: 43.

13. Isla M, Málaga $\mathrm{O}$, Yarlequé A. Características bioquímicas y acción biológica de una hemorragina del veneno de Bothrops brazili. An Fac med. 2003; 64(3): 159-166.

14. Laemmli UK. Cleavage of structural proteins during the assembly of the head of bacteriophage T4. Nature. 1970; 256:680-684. 
15. Ouchterlony O, Nilsson L. lmmunodiffusion and immunoelectrophoresis. Handbook of immunological methods, Vol. 1: Immunochemistry. Oxford: Blackwell Scientific Publications; 1978.

16. Yarlequé A, Vivas D, Inga R, Rodríguez E, Sandoval G, Pessah S, Bonilla C. Acción del antiveneno botrópico polivalente sobre las actividades proteolíticas presentes en los venenos de serpientes peruanas. Rev Peru Med Exp Salud Publica. 2008; 25(2):169-73.

17. Pantigoso C, Escobar E, Málaga O, Yarlequé A. Aislamiento y algunas propiedades de la atroxina, una proteinasa del veneno de la serpiente peruana Botrhops atrox «jergón». Acta Cien Venez. 1996; 47: 67-73.

18. López-Lozano J, de Sousa M, Ricart C, Chávez-Olortegui C, Sanchez E, Muniz E, Bührnheim P, Morhy L. Ontogenetic variation of metalloproteinases and plasma coagulant activity in venoms of wild Bothrops atrox specimens from Amazonian rain forest. Toxicon 2002; 40(7):997-1006.

19. Cortéz R. Aislamiento, propiedades bioquímicas y acción fibrinogenolítica de una proteasa del veneno de la serpiente Bothrops pictus "jergón de la costa". [Tesis de pregrado]. Lima: Universidad Nacional Mayor de San Marcos; 1997.

20. Rodríguez E, Yarlequé A. Aislamiento y algunas propiedades de la Proteinasa I del veneno de la serpiente peruana Lachesis muta. Acta Cien Venez. 1991; 42: 219-225.

21. Azañero A, Escobar E, Yarlequé A. Purificación de una enzima proteolítica del veneno de Bothrops brazili y estudio de su actividad sobre fibrinógeno. Rev per biol. 2000; 7(1): 67-73.

22. Sánchez E, Gabriel L, Gontijo S, Gremski L, Veiga S, Evangelista K, Eble J, Richardson M. Structural and functional characterization of a P-III metalloproteinase, leucurolysin-B, from Bothrops leucurus venom. Arch Biochem Biophys. 2007; 468: 193-204. 